\title{
Intensification of IDegAsp Twice Daily (Adding Insulin Aspart vs. Switching To Basal-Bolus): Exploratory Randomized Trial in Type 2 Diabetes
}

\author{
Wan Mohamaed Wan Bebakar · Louis Chaykin • Malene Lundgren Hersløv • \\ Søren Rasmussen
}

Received: September 26, 2016 / Published online: November 16, 2016

(c) The Author(s) 2016. This article is published with open access at Springerlink.com

\begin{abstract}
Introduction: In a preceding trial comparing two different titration schemes, insulin degludec/insulin aspart (IDegAsp) showed good efficacy for achieving $\mathrm{HbA}_{1 \mathrm{c}}<7 \%$ when administered twice daily (BID) in patients with uncontrolled type 2 diabetes (T2D). However, poor glycemic control persisted in a minority of patients. The current exploratory trial investigated the efficacy and safety of intensifying IDegAsp BID treatment in these patients by either adding a once-daily (OD)
\end{abstract}

Enhanced content To view enhanced content for this article go to http://www.medengine.com/Redeem/ 3717F06066F5175E.

Electronic supplementary material The online version of this article (doi:10.1007/s13300-016-0213-8) contains supplementary material, which is available to authorized users.

W. M. W. Bebakar $(\bowtie)$

School of Medical Sciences Universiti Sains

Malaysia, 16150 Kota Bharu, Kelantan, Malaysia

e-mail: wanmohd@usm.my

\section{Chaykin}

Meridien Research, 5700 E State Road 64,

Bradenton, FL 34208, USA

M. L. Hersløv · S. Rasmussen

Novo Nordisk A/S, Vandtaarnsvej 114, 2860 Søborg, Denmark bolus injection of insulin aspart (IAsp) or by switching to a basal-bolus regimen of insulin degludec (IDeg) plus IAsp taken three times a day (TID).

Method: A 26-week, randomized, open-label, phase $3 \mathrm{~b}$, treat-to-target trial in which 40 patients with T2D who had not reached target $\mathrm{HbA}_{1 \mathrm{c}} \leq 7.0 \%$ following previous 26-week treatment intensification with IDegAsp BID \pm 3 oral antidiabetic agents (OADs) were randomized (1:1) to receive IDegAsp BID + IAsp OD $(n=20)$ or IDeg OD + IAsp TID $(n=20)$.

Results: Mean baseline $\mathrm{HbA}_{1 \mathrm{c}}$ was $7.9 \%$ in the IDegAsp BID + IAsp OD group and $7.7 \%$ in the IDeg OD + IAsp TID group. After 26 weeks, the estimated mean change in $\mathrm{HbA}_{1 \mathrm{c}}$ from baseline was $0.05 \%$ points in the IDegAsp BID + IAsp OD group and $-0.49 \%$ points for IDeg OD + IAsp TID: estimated treatment difference (ETD) [95\% confidence interval] $0.54 \%$ [0.09; 0.99], $p=0.021$. Few achieved $\mathrm{HbA}_{1 \mathrm{c}}<7 \%$ in IDegAsp BID + IAsp OD (four patients) and IDeg OD + IAsp TID groups (five patients). Fasting plasma glucose, hypoglycemia, and adverse events were similar between groups. 
Conclusion: When used as intensification regimens in patients who failed to achieve target $\mathrm{HbA}_{1 \mathrm{c}}$ during 26-week IDegAsp BID treatment, $\mathrm{HbA}_{1 \mathrm{c}}$ improvements were numerically greater with IDeg OD + IAsp TID compared with IDegAsp BID + IAsp OD. No new safety issues were identified. However, the small, selective sample means clinical generalizations should be made with caution.

Funding: Novo Nordisk.

Clinicaltrials.gov identifier: NCT01814137.

Keywords: Glycemic control; Insulin degludec/ insulin aspart; Insulin intensification

\section{INTRODUCTION}

Insulin degludec/insulin aspart (IDegAsp) is the first soluble co-formulation of two separate insulins, containing 70\% insulin degludec (IDeg) and 30\% insulin aspart (IAsp) in a single injection, retaining the properties of the original formulations [1]. IDeg forms soluble multi-hexamers at the injection site and is slowly absorbed, while IAsp hexamers dissociate upon injection into rapidly absorbed monomers. This results in a novel pharmacokinetic and pharmacodynamic profile compared with premix insulins, characterized by the distinct basal to prandial effect observed with IDegAsp [2], with a stable basal insulin coverage over a 24-h period due to the IDeg component, and without the need for resuspension. IDegAsp is recommended to be administered once (OD) or twice daily (BID) with main meal(s) [3].

Two clinical trials in the IDegAsp clinical development program showed that, compared with biphasic insulin aspart 30 (BIAsp 30), treatment intensification with IDegAsp BID over 26 weeks results in fewer confirmed, nocturnal confirmed, and severe hypoglycemic episodes whilst reaching the non-inferiority margin for mean reduction in $\mathrm{HbA}_{1 \mathrm{c}}[4,5]$. A combined analysis of these two trials reports that estimated rate ratios of overall confirmed, nocturnal confirmed, and severe hypoglycemic events with IDegAsp BID compared with BIAsp 30 were 0.69 [95\% CI 0.55; 0.87], 0.38 [95\% CI $0.25 ; 0.58$ ], and 0.16 [95\% CI $0.04 ; 0.59$ ], respectively [6].

A preceding trial to the current one added further understanding of two different titration algorithms (e.g., a "simple" algorithm using twice-weekly dosing adjustments and a "stepwise" algorithm using once-weekly dose adjustment) of the new co-formulation of IDegAsp BID, when used as an intensification regimen in patients inadequately controlled with a basal-only regimen (i.e., insulin glargine OD) [7]. After 26 weeks of IDegAsp BID treatment, $67 \%$ of patients successfully achieved the recommended $\mathrm{HbA}_{1 \mathrm{c}}$ target of less than 7\%, accompanied by significant reductions in fasting plasma glucose (FPG), while rates of hypoglycemia were in line with previous trials of intensification with IDegAsp BID [4-8].

At the end of the preceding trial, a small sample of patients were left still experiencing poor glycemic control $\left(\mathrm{HbA}_{1 \mathrm{c}} \geq 7.0 \%\right)$ [7]. These represent a group of difficult-to-treat patients with type 2 diabetes (T2D), and it raises the question of which treatment pathway is appropriate for those who do not respond to intensification with IDegAsp BID. Therefore, in the current trial, two treatment strategies were investigated as potential intensification options: (a) adding a single injection of bolus insulin at the third main meal (i.e., IAsp OD) in addition to IDegAsp BID, in order to provide additional mealtime glycemic control; 
(b) switching to a full basal-bolus regimen (i.e., IDeg + IAsp three times a day [TID]).

\section{METHODS}

\section{Sample}

The sample was recruited from 68 male and female patients ( $\geq 18$ years with a body mass index $[\mathrm{BMI}] \leq 40 \mathrm{~kg} / \mathrm{m}^{2}$ ) who had failed to achieve glycemic control following 26 weeks of treatment with IDegAsp BID [7].

Key exclusion criteria were the presence of cardiovascular (CV) events (e.g., stroke) between the start of the preceding trial and consenting to the present trial, uncontrolled hypertension (i.e., systolic blood pressure $\geq 180 \mathrm{mmHg}$ and/or diastolic blood pressure $\geq 100 \mathrm{mmHg}$ ) and the presence of recurrent severe hypoglycemia (more than one event within the previous 12 months), or hypoglycemic unawareness, as evaluated by the investigator. Dipeptidyl peptidase 4 inhibitors (DPP-4) and/or metformin was allowed only if continued from the preceding trial; commencement of new oral antidiabetic agents (OADs) during the trial was prohibited.

Of the 68 patients eligible for screening, 47 consented to enter into the current trial, of which seven failed screening (six patients failed because their $\mathrm{HbA}_{1 \mathrm{c}}$ was less than $7 \%$ and one patient failed because of impaired renal function). Forty patients were randomized and 10 patients withdrew during the trial, which resulted in 30 completers (15 completers in each treatment group). The proportion of subjects withdrawn from the trial was the same between the two treatment groups. One subject (in the IDeg OD + IAsp TID group) was withdrawn because of an adverse event (AE). There was no apparent pattern in the withdrawals and no apparent clustering of withdrawals at any specific time point during the trial.

\section{Design}

This was a 26-week, randomized, open-label, phase $3 \mathrm{~b}$, treat-to-target, exploratory trial in which patients were randomized 1:1 to either IDegAsp BID + IAsp OD \pm OADs or IDeg $\mathrm{OD}+\mathrm{IAsp}$ TID \pm OADs. Participating countries were the USA $(n=26)$, Malaysia $(n=11)$, Germany $(n=2)$, and Turkey $(n=1)$.

\section{Compliance with Ethics Guidelines}

All procedures followed were in accordance with the ethical standards of the responsible committee on human experimentation (institutional and national) and with the Declaration of Helsinki 1975, as revised in 2013, and Good Clinical Practice (International Conference on Harmonisation). Informed consent was obtained from all patients for being included in the trial.

\section{Trial Endpoints}

The primary endpoint was change from baseline in $\mathrm{HbA}_{1 \mathrm{c}}$ after 26 weeks. The secondary endpoints were FPG, mean 8-point self-measured plasma glucose (SMPG), post-prandial glucose (PPG) increment, insulin dose, and body weight.

Safety endpoints included the total number of AEs in each treatment group, the number of serious adverse events (SAEs), the AE rate per 100 patient-years of exposure (PYE), and the number of patients withdrawn due to AEs. Confirmed hypoglycemic episodes included episodes with a measured plasma glucose (PG) 
value of less than $3.1 \mathrm{mmol} / \mathrm{L}$ or severe episodes (severe defined as requiring assistance from another person to treat). Confirmed hypoglycemic events that occurred during 0001-0559 hours (both inclusive) were classified as nocturnal.

\section{Insulin Dose and Titration}

In the IDegAsp BID + IAsp OD treatment arm, IDegAsp was administered with breakfast and the evening meal and IAsp was administered with lunch. Patients restarted their end of trial (EOT) IDegAsp BID dose used in the preceding trial [7] and the lunchtime IAsp starting dose was 4 units (U).

In the IDeg OD + IAsp TID treatment arm, IDeg was administered at any time of the day. IAsp was administered with breakfast, lunch, and the evening meal. The starting IDeg dose was $70 \%$ of the EOT total daily dose from the preceding trial [7]. The starting IAsp dose was $30 \%$ of the total EOT dose from the preceding trial divided into three doses per day.

IDeg and IDegAsp were titrated as per the stepwise algorithm in the preceding trial [7]. IDegAsp was dosed according to weekly adjustments based on the lowest of 3 days' pre-breakfast and pre-evening meal SMPG measurements. IDeg was dosed according to the lowest of three consecutive days' pre-breakfast SMPG measurements prior to titration. IAsp was dosed according to the lowest of three consecutive days' SMPG measurements at the following timepoints: breakfast dose was titrated according to the lowest of the pre-lunch SMPG measurements; lunch dose was titrated according to the lowest of the pre-dinner SMPG measurements; evening meal dose was titrated according to the lowest of the bedtime SMPG measurements. The dose of IAsp could be reduced at the discretion of the investigator.

\section{Statistics}

Endpoints derived at 26 weeks were analyzed statistically using the analysis of covariance method (ANCOVA) to estimate mean treatment effects (i.e., least-square means) with 95\% confidence intervals (CIs). The primary endpoint was analyzed with an ANCOVA with treatment, sex, and region entered as fixed factors. Age and baseline $\mathrm{HbA}_{1 \mathrm{c}}$ were entered as covariates. Region had three levels: North America, Europe, and Asia. The number of treatment-emergent hypoglycemic episodes was analyzed using a negative binomial regression model with a log-link function and the logarithm of the time period for which a hypoglycemic episode was considered treatment emergent as offset. The model included treatment, sex, and region as fixed factors, and age as covariates. Furthermore, insulin dose in units and units per kilogram was logarithmically transformed and analyzed separately using an ANCOVA method with treatment, sex, and region as fixed factors, and age and the relevant baseline value as covariates. Changes from baseline in FPG and body weight after 26 weeks of treatment were analyzed using an ANCOVA method with treatment, sex, and region as fixed factors, and age and baseline values as covariates. Mean 8-point SMPG and PPG increment were analyzed separately using an ANCOVA method with treatment, sex, and region as fixed factors, and age and the relevant baseline value as covariates. $P$ values were only computed for the primary endpoint. Missing values were imputed using the last observation carried forward (LOCF) method. 


\section{RESULTS}

The baseline characteristics of the patients are presented in Table 1, per respective treatment group. There was a gender imbalance between the two treatment arms, with more male patients being randomly assigned in the IDegAsp BID + IAsp OD arm vs. the IDeg OD + IAsp TID arm. Differences were also observed between treatment arms in baseline $\mathrm{HbA}_{1 \mathrm{c}}$, mean body weight, and FPG (Table 1).

Mean EOT $\mathrm{HbA}_{1 \mathrm{c}}$ was $8.0 \%$ in the IDegAsp BID + IAsp OD treatment arm and $7.4 \%$ in the IDeg OD + IAsp TID treatment arm (Fig. 1). The estimated mean change in $\mathrm{HbA}_{1 \mathrm{c}}$ from baseline was $0.05 \%$ points in the IDegAsp BID + IAsp OD treatment arm and $-0.49 \%$ points in the IDeg OD + IAsp TID arm estimated treatment difference (ETD) [95\% CI] 0.54\% [0.09; 0.99], $p=0.021$. The proportion of patients reaching $\mathrm{HbA}_{1 \mathrm{c}}<7 \%$ was $27 \%(n=4)$ in the IDegAsp BID + IAsp OD arm compared with 33\% $(n=5)$ of patients in the IDeg OD + IAsp TID arm.
Mean FPG for the IDegAsp BID + IAsp OD treatment arm was $6.5 \mathrm{mmol} / \mathrm{L}$, with a mean reduction of $0.80 \mathrm{mmol} / \mathrm{L}$ from baseline to EOT. The mean FPG for the IDeg OD + IAsp TID treatment arm was $6.2 \mathrm{mmol} / \mathrm{L}$, with a mean reduction of $2.57 \mathrm{mmol} / \mathrm{L}$ from baseline). The difference was not statistically significantly different: ETD [95\% CI] $0.67 \mathrm{mmol} / \mathrm{L}$ [-1.09; 2.42].

At 26 weeks, the mean 8-point SMPG was $7.8 \mathrm{mmol} / \mathrm{L}$ in the IDegAsp BID + IAsp OD treatment arm, which was a $0.9 \mathrm{mmol} / \mathrm{L}$ reduction from baseline. In the IDeg OD + IAsp TID arm, the respective values were $7.3 \mathrm{mmol} / \mathrm{L}$ and $2.0 \mathrm{mmol} / \mathrm{L}$, respectively. There was no significant difference between treatment arms: ETD [95\% CI]: $0.85 \mathrm{mmol} / \mathrm{L}$ $[-0.25 ; 1.96]$. No statistically significant difference in PPG increment after 26 weeks was shown between the treatments: ETD [95\% CI] $0.11 \mathrm{mmol} / \mathrm{L}$ [-0.84; 1.06$]$.

EOT mean insulin dose was similar in both treatment arms: IDegAsp BID + IAsp OD, $1.72 \mathrm{U} / \mathrm{kg} \quad[163 \mathrm{U}] ; \quad$ IDeg OD + IAsp TID,

Table 1 Baseline characteristics

\begin{tabular}{lll}
\hline Characteristic & IDegAsp BID + IAsp OD & IDeg OD + IAsp TID \\
\hline Full analysis set (FAS), $n$ & 20 & 20 \\
Female/male, \% & $25: 75$ & $45: 55$ \\
White/Black/Asian/Other, \% & $50: 20: 30: 0$ & $65: 5: 30: 0$ \\
Ethnicity: Hispanic or Latin American & 10 & 15 \\
Age, years & $58(8.0)$ & $56.9(8.1)$ \\
Body weight, kg & $90.4(20.7)$ & $85.3(20.2)$ \\
BMI, kg/m & $31.7(5.3)$ & $31.1(6.2)$ \\
Duration of diabetes, years & $12.4(9.0)$ & $11.3(6.1)$ \\
HbA $\mathrm{lc}_{\mathrm{lc}}^{2}$ & $7.9(0.7)$ & $7.7(0.6)$ \\
$\mathrm{FPG}, \mathrm{mmol} / \mathrm{L}$ & $7.3(3.5)$ & $8.6(2.8)$ \\
Insulin dose, U/kg & 1.36 & 1.20 \\
\hline
\end{tabular}

Data are mean (SD) unless otherwise stated, and taken from baseline $B M I$ body mass index, FPG fasting plasma glucose 

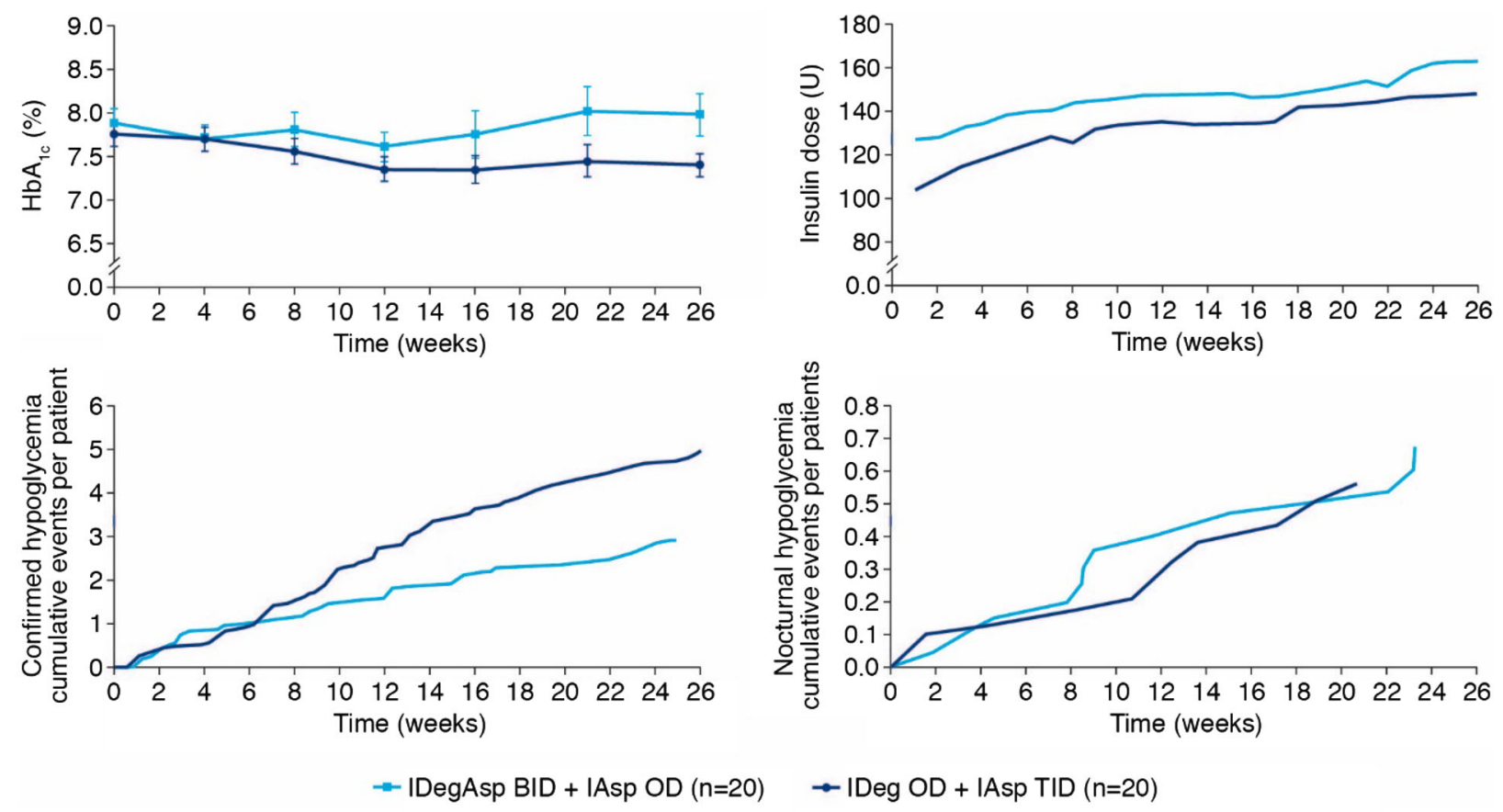

BID, twice daily; IAsp, insulin aspart; IDegAsp, insulin aspart/insulin degludec; IDeg, insulin degludec; OD, once daily

Fig. 1 Change from baseline in $\mathrm{HbA}_{1 \mathrm{c}}$, insulin dose, and hypoglycemia (confirmed and nocturnal) at 26 weeks

$1.71 \mathrm{U} / \mathrm{kg}$ [148 U] (Fig. 1). The basal dose ratio $(\mathrm{U} / \mathrm{kg})$ for IDegAsp BID + IAsp OD versus IDeg OD + IAsp TID was 1.10, with the bolus dose ratio being 0.89 and the total insulin dose ratio being 1.01. The basal component accounted for $61 \%$ and bolus insulin accounted for $39 \%$ of the total daily insulin dose in the IDegAsp BID + IAsp OD group, while in the IDeg OD + IAsp TID group, the relevant percentages were $55 \%$ and $45 \%$, respectively.

Mean EOT body weight was $92.3 \mathrm{~kg}$ and $87.2 \mathrm{~kg}$ for the IDegAsp BID + IAsp OD treatment arm and the IDeg OD + IAsp TID arm, respectively. There was a $1.9 \mathrm{~kg}$ increase from baseline in both arms, translating into no significant difference in body weight after 26 weeks: ETD [95\% CI]: $0.01 \mathrm{~kg}[-1.79 ; 1.80]$.

At EOT, $70 \%(n=14)$ of patients reported confirmed hypoglycemic events in the IDegAsp BID + IAsp OD treatment arm and 80\% $(n=16)$ in the IDeg OD + IAsp TID treatment arm. The rate of confirmed hypoglycemia was 6.22 episodes/PYE in the IDegAsp BID + IAsp OD treatment arm and 10.85 episodes/PYE in the IDeg OD + IAsp TID arm; rate ratio [RR] [95\% CI] $0.68 ; \quad[0.33 ; 1.41]$ (Fig. 1). Nocturnal confirmed hypoglycemia was reported by $35 \%$ $(n=7)$ of patients in the IDegAsp BID + IAsp OD treatment arm and 30\% $(n=6)$ in IDeg OD + IAsp TID arm. The rate of nocturnal confirmed hypoglycemia was 1.50 episodes/ PYE in the IDegAsp BID + IAsp OD arm and 1.37 episodes/PYE in the IDeg OD + IAsp TID arm; RR [95\% CI] 1.10; [0.36; 3.42] (Fig. 1). Only two patients reported severe hypoglycemia events, both in the IDegAsp BID + IAsp OD treatment arm.

There were 33 AEs in the IDegAsp BID + IAsp OD treatment arm and 45 AEs in the IDeg OD + IAsp TID arm. There was one adverse 
cardiac event (atrial fibrillation) in the IDegAsp BID + IAsp OD treatment arm and none in the IDeg OD + IAsp TID arm. One event of stroke was positively adjudicated in the IDeg OD + IAsp TID arm and none in the IDegAsp BID + IAsp OD arm. There were two SAEs in the IDegAsp BID + IAsp OD treatment arm and three in the IDeg OD + IAsp TID arm. None of the SAEs were judged by the investigator to be "possibly" or "probably" related to the trial product or to bolus insulin, and no deaths were reported in the trial. Further safety data are presented in Supplementary Table S1.

\section{DISCUSSION}

In previous IDegAsp clinical trials, patients with T2D inadequately controlled on OADs plus an alternative insulin regimen (i.e., basal-only insulin detemir, insulin glargine administered OD or BID; a premix, analogue insulin regimen administered BID; or an insulin regimen containing a rapid-acting component) have shown similar reduction in $\mathrm{HbA}_{1 \mathrm{c}}$ and fewer hypoglycemic episodes following intensification with IDegAsp BID versus comparator regimens (i.e., basal-prandial, premix BID)—with the responder rate for $\mathrm{HbA}_{1 \mathrm{c}}<7 \%$ following IDegAsp BID treatment ranging from $48.2 \%$ to $56.5 \%[4-6,8]$. In the preceding titration trial comparing a simple vs. stepwise titration of IDegAsp BID in patients previously inadequately controlled on basal insulin, the overall responder rate for intensification with IDegAsp BID was 67\% [7], which is higher than that seen in the earlier studies [4-6, 8].

Nevertheless, there was a small population of more difficult-to-treat patients, for whom poor glycemic control persisted despite insulin intensification beyond basal-only treatment
[7]. This scenario is clinically interesting and is commonly encountered in real-world clinical practice. Therefore, the current trial provides relevant treatment information for clinicians regarding the efficacy and safety of further insulin intensification using two different strategies. However, as a result of the low number of patients participating in this exploratory trial, the results should be confirmed by further clinical trials.

Adding IAsp OD treatment to an IDegAsp $B I D$ regimen resulted in the maintenance of $\mathrm{HbA}_{1 \mathrm{c}}$ levels over the 26-week period, while the switch to an IDeg OD + IAsp TID regimen significantly reduced $\mathrm{HbA}_{1 \mathrm{c}}$ by $0.49 \%$. As may be expected for this difficult-to-treat population, a small proportion of patients achieved $\mathrm{HbA}_{1 \mathrm{c}}<7 \%$ in both IDegAsp BID + IAsp OD and IDeg OD + IAsp TID groups (four vs. five patients, respectively). The reduction in FPG was numerically higher with IDeg OD + IAsp TID compared with IDegAsp BID + IAsp OD, although no statistical difference between the groups was observed, and the mean increase in body weight was similar for both treatment arms.

The frequency of AEs observed during treatment was similar in both treatments and in line with existing trials, with few severe hypoglycemic episodes being reported and no new safety issues being identified [4-8].

As recommended in the most recent American Diabetes Association (ADA) guidelines, treatment for T2D should be personalized, culturally appropriate, and take into account the patient's own preferences and expectations [9]. As demonstrated in the current trial, treatment adaptations may be challenging for some patients. Whilst patients switching to IDeg OD + IAsp TID did experience an approximate $0.5 \%$ reduction in $\mathrm{HbA}_{1 \mathrm{c}}$, alternative combination regimens (e.g., 
combination insulins plus glucagon-like peptide-1 receptor agonists [GLP-1RAs] and sodium-glucose co-transporter-2 [SGLT2] inhibitors) may need to be considered. However, data from clinical trials regarding intensification of IDegAsp BID in combination with such treatments are not currently available.

The current trial had a number of limitations. The sample was smaller than originally predicted for this exploratory trial, primarily because of the success of the preceding trial in achieving glycemic targets [7], so the results should be interpreted with caution. Furthermore, as a result of the participation of a specified trial population (i.e., those who had failed to reach glycemic targets on 26 weeks of IDegAsp BID treatment, following initial failure on basal insulin), the results should not be generalized to the wider population of all patients with T2D.

\section{CONCLUSION}

Treatment intensification of a sample of patients that failed to reach glycemic targets following 26 weeks of treatment with IDegAsp BID resulted in $\mathrm{HbA}_{1 \mathrm{c}}$ being significantly reduced by a subsequent 26-week IDeg OD + IAsp TID regimen compared with a 26-week IDegAsp BID + IAsp OD regimen, while no new safety issues were identified. Alternative treatment intensification regimens for difficult-to-treat patients failing IDegAsp BID therapy need to be further studied.

\section{ACKNOWLEDGEMENTS}

Sponsorship and article processing charges for this study were funded by Novo Nordisk. All named authors meet the International Committee of Medical Journal Editors (ICMJE) criteria for authorship for this manuscript, take responsibility for the integrity of the work as a whole, and have given final approval to the version to be published. Medical writing and submission support were provided by Liam Gillies and Gabrielle Parker of Watermeadow Medical, an Ashfield company, part of UDG Healthcare plc, funded by Novo Nordisk.

Disclosures. Professor Wan Bebakar has participated in advisory boards for Novo Nordisk. Dr Chaykin has participated in speakers' bureau for Novo Nordisk. Dr Hersløv is an employee of Novo Nordisk. Dr Rasmussen is an employee of Novo Nordisk.

Compliance with Ethical Guidelines. All procedures followed were in accordance with the ethical standards of the responsible committee on human experimentation (institutional and national) and with the Declaration of Helsinki 1975, as revised in 2013. Informed consent was obtained from all patients for being included in the trial.

Data Availability. The datasets during and/ or analyzed during the current study are available from the corresponding author on reasonable request.

Open Access. This article is distributed under the terms of the Creative Commons Attribution-NonCommercial 4.0 International License (http://creativecommons.org/licenses/ by-nc/4.0/), which permits any noncommercial use, distribution, and reproduction in any medium, provided you give appropriate credit to the original author(s) and the source, provide a link to the Creative Commons license, and indicate if changes were made. 


\section{REFERENCES}

1. Havelund S, Ribel U, Hubálek F, Hoeg-Jensen T, Wahlund P-O, Jonassen I. Investigation of the physico-chemical properties that enable co-formulation of basal insulin degludec with fast-acting insulin aspart. Pharm Res. 2015;32:2250-8.

2. Heise T, Tack CJ, Cuddihy R, et al. A new-generation ultra-long-acting basal insulin with a bolus boost compared with insulin glargine in insulin-naive people with type 2 diabetes: a randomized, controlled trial. Diabetes Care. 2011;34:669-74.

3. European Medicines Agency. Ryzodeg summary of product characteristics. 2014. http://ec.europa.eu/ health/documents/community-register/2013/201301 21124986/anx_124986_en.pdf. Accessed Aug 2015.

4. Fulcher GR, Christiansen JS, Bantwal G, et al. Comparison of insulin degludec/insulin aspart and biphasic insulin aspart 30 in uncontrolled, insulin-treated type 2 diabetes: a phase $3 a$, randomized, treat-to-target trial. Diabetes Care. 2014;37:2084-90.

5. Kaneko S, Chow F, Choi DS, et al. Insulin degludec/ insulin aspart versus biphasic insulin aspart 30 in
Asian patients with type 2 diabetes inadequately controlled on basal or pre-/self-mixed insulin: a 26-week, randomised, treat-to-target trial. Diabetes Res Clin Pract. 2015;107:139-47.

6. Christiansen JS. Lower rates of hypoglycemia during maintenance treatment with IDegAsp versus BIAsp 30: a combined analysis of two phase 3a studies in type 2 diabetes. J Diabetes. 2016;8(5):720-8.

7. Gerety G, Bebakar WM, Chaykin L, et al. Treatment intensification with insulin degludec/insulin aspart twice daily: randomized study to compare simple and step-wise titration algorithms. Endocr Pract. 2016;22:546-54.

8. Rodbard HW, Cariou B, Pieber TR, Endahl LA, Zacho J, Cooper JG. Treatment intensification with an insulin degludec (IDeg)-insulin aspart (IAsp) co-formulation twice daily compared with basal IDeg and prandial IAsp in type 2 diabetes: a randomized, controlled phase 3 trial. Diabetes Obes Metab. 2016;18:274-80.

9. American Diabetes Association. Standards of medical care in diabetes-2016. Diabetes Care. 2016;39:S1. 